\title{
Endoscopic removal of migrated esophageal stent - the "grasper and pusher" method
}

A 79-year-old man with metastatic adenocarcinoma of the cardia was submitted to palliative chemotherapy and esophageal stenting for relief of dysphagia. After the fourth cycle of chemotherapy he was admitted to the emergency department complaining of dysphagia. At endoscopy a significant regression of the lesion size and migration of the stent into the stomach were noticed. The standard gastroscope $(9.8 \mathrm{~mm})$ was easily inserted into the gastric chamber. In order to facilitate the use of the proximal lasso system to close the proximal end of the stent, the standard gastroscope was switched to the therapeutical scope, and a 10-Fr biliary stent pusher was inserted into the largest operational channel followed by a grasp forceps ( $\bullet$ Fig.1). The lasso was grasped and pulled back into the pusher while the endoscopist's assistant advanced it against the stent. This maneuver allowed the constraining of the proximal end of the stent, facilitating its removal ( $\bullet$ Fig. 2 and $\odot$ Video 1 ).

The occurrence of esophageal stent migration after chemoradiation therapy can be as high as 40\% [1]. Esophageal stent migration is not an emergency. Indeed, some authors advocate a "wait and see" approach [2]. On the other hand there are some reports of distal migration with intestinal obstruction and impaction requiring surgery [2-4]. In our view, endoscopic removal of a distally migrated esophageal stent is desirable whenever possible. However, the withdrawal may be a challenging procedure [5]. Many different approaches for safe endoscopic removal of a migrated stent have been described, such as the use of an overtube, a snare combined with a rat-toothed forceps, and an endoloop device [6].

\section{Video 1}

Endoscopic removal of the migrated esophageal stent using the "grasper and pusher" method.

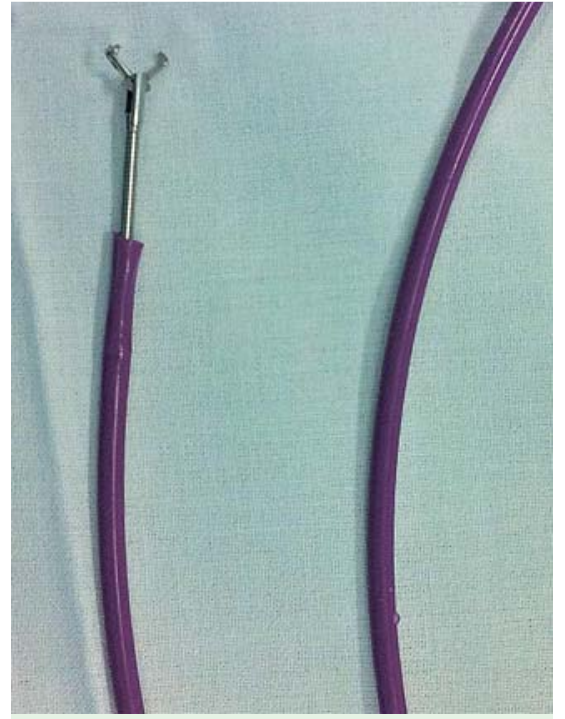

Fig. 1 Rat-toothed grasper inside the biliary stent pusher.

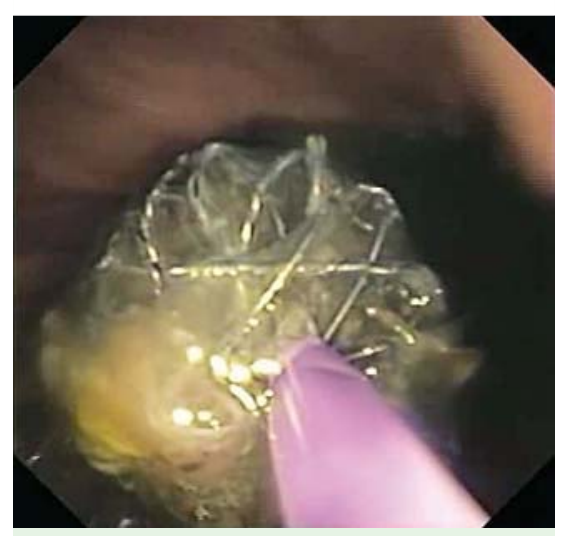

Fig. 2 Stent border constrained by the grasper and pusher together.

We believe that the "grasper and pusher" method is an elegant and safe technique to deal with a migrated esophageal stent, especially when a significant reduction in tumor size has occurred allowing the passage of a therapeutic endoscope.

\section{Endoscopy_UCTN_Code_TTT_1AO_2AZ}

Competing interests: None
B. Martins ${ }^{1}$, M. P. Sorbello ${ }^{1}$, F. Retes ${ }^{1}$, F. S. Kawaguti ${ }^{1}$, M. S. Lima ${ }^{1}$, F. Y. Hondo ${ }^{1}$, G. Stelko ${ }^{2}$, U. Ribeiro ${ }^{1}$, F. Maluf-Filho ${ }^{1}$

${ }^{1}$ Department of Gastroenterology, Cancer Institute, University of São Paulo Medical School, São Paulo, Brazil

${ }^{2}$ Department of Oncology, Cancer Institute, University of São Paulo Medical School, São Paulo, Brazil

\section{References}

1 Langer FB, Schoppmann SF, Prager G et al. Temporary placement of self-expanding oesophageal stents as bridging for neo-adjuvant therapy. Ann Surg Oncol 2010; 17: 470-475

2 De Palma GD, Iovino P, Catanzano C. Distally migrated esophageal self-expanding metal stents: wait and see or remove? Gastrointest Endosc 2001; 53: 96-98

3 Begbie S, Briggs G, Levi J. A late complication of palliative stenting of malignant oesophageal obstruction. Aust N Z J Med 1996; 26 : $115-115$

4 Ho HS, Ong HS. A rare life-threatening complication of migrated nitinol self-expanding metallic stent (Ultraflex). Surg Endosc 2004; 18: $347-347$

5 Ramirez FC, Dennert B, Zierer ST et al. Esophageal self-expandable metallic stents - indications, practice, techniques, and complications: results of a national survey. Gastrointest Endosc 1997; 45: 360-364

6 De Ronde T, Martinet JP, Melange M. Easy removal of migrated self-expanding esophageal metal stent using an endoloop device. Gastrointest Endosc 2000; 52: 125 - 127

\section{Bibliography}

DOI http://dx.doi.org/

10.1055/s-0031-1291496

Endoscopy 2012; 44: E10

(c) Georg Thieme Verlag KG

Stuttgart · New York

ISSN 0013-726X

\section{Corresponding author}

\section{Bruno, MD}

Endoscopy Unit

São Paulo University Medical School

Cincinato Braga Street, 37

São Paulo SP - 01333-011

Brazil

Fax: +55-11-32514799

bcm.bruno@gmail.com 